\title{
Numerical Simulation of a Proton Exchange Membrane (PEM) Fuel Cell with Rectangular and Triangular Cross-Section Area Channels
}

\author{
Amin Etminan, Zambri Harun
}

\begin{abstract}
In the present study, the performance of a Proton Exchange Membrane (PEM) fuel cell is numerically simulated for two channels with rectangular and triangular cross-section areas. A series of simulations is carried out to investigate both the influence of the humidity and the temperature of the input gas as two effective parameters on the performance of a PEM, which change from $10 \%$ to $100 \%$ and $30^{\circ} \mathrm{C}$ to $60^{\circ} \mathrm{C}$, respectively. Numerical results indicate that more moisturized input gas produces a higher output voltage for both geometries. Furthermore, the triangular duct generates a higher output voltage in comparison with the rectangular duct, particularly, in the case of the parallel flow. In addition, the temperature of the input gas remarkably enhances the output voltage of the PEM. A qualitative agreement is achieved by comparing the present results to existing experimental data.
\end{abstract}

Keywords : Fuel cell, Numerical simulation, , Proton Exchange Membrane (PEM), PEM performance.

\section{INTRODUCTION}

Fuel cells are currently used in a vast array of technologies, and are specifically used in vehicles and aerospace applications. A fuel cell is an electrochemical device that converts the chemical energy provided by a fuel into an electric current through an electrochemical reaction [1]. Fuel cells are completely different from batteries in that they require a continuous source of fuel and oxygen (usually from the air) to sustain the chemical reaction. Conversely, in a battery, the electric energy is produced from chemicals already available there. Therefore, a fuel cell can generate a nonstop electric current as long as fuel and oxidants are supplied [2 and 3]. Some of the most common types of fuel cells are the Proton Exchange Membrane Fuel Cell (PEMFC), the Phosphoric Acid Fuel Cell (PAFC), the Solid Acid Fuel Cell (SAFC), the Alkaline Fuel Cell (AFC), high-temperature fuel cells, and the electric storage fuel cell. Still, all of these types of fuel cells work the same way via an anode, an electrolyte, and a cathode. The net output of the

Revised Manuscript Received on March 16, 2020.

* Correspondence Author

Amin Etminan*, Mechanical Engineering Department, Memorial University of Newfoundland (MUN), St. John's, NL, Canada. Email: aetminan@mun.ca

Zambri Harun, Department of Mechanical \& Materials Engineering, Universiti Kebangsaan Malaysia, Bangi, Malaysia.

(C) The Authors. Published by Blue Eyes Intelligence Engineering and Sciences Publication (BEIESP). This is an open access article under the CC BY-NC-ND license (http://creativecommons.org/licenses/by-nc-nd/4.0/) two chemical reactions is that fuel is consumed, water and carbon dioxide are created, and a continuous electric current is generated. Figure 1 shows different segments of a PEM and two specific chemical reactions that occur on the anode and cathode to produce an output electric current. On the anode, a catalyst causes the fuel to experience an oxidation reaction that generates protons, positively charged hydrogen ions, and electrons. The protons flow from the anode to the cathode through the electrolyte after the reaction. Simultaneously, electrons are moved from the cathode to the anode through an external circuit, producing Direct Current (DC) electricity. On the cathode, another catalyst causes hydrogen ions, electrons, and oxygen to react and produce water [1].

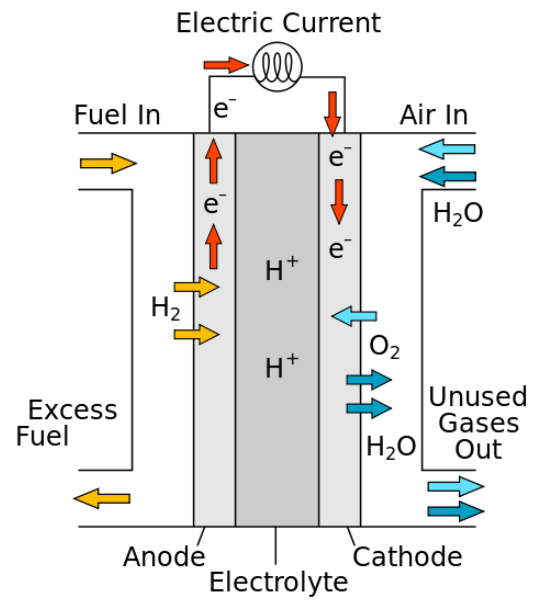

Fig. 1. Schematic of a PEM; fuel and air flows and chemical reactions.

In the last two decades, many numerical and experimental investigations regarding the performance of different flow directions, channel configurations, and their optimization in PEM fuel cells have been carried out [4-22]. Three different flow patterns; interdigitated, serpentine, and spiral interdigitated, were numerically simulated by Cha et al. [4] using Computational Fluid Dynamics (CFD) method. The channel size was varied from a macro size (greater than 500 $\mu \mathrm{m})$ to a micro size (less than $100 \mu \mathrm{m}$ ) to find the optimal size of the channel. The researchers realized that the pressure loss and the flow structure in the cathode compartment were major factors in determining the optimal size of the channels.

Using Computational Fuel Cell Dynamics (CFCD) in fully three-dimensional interfaces between mass transport and electrochemical kinetics of a polymer electrolyte fuel cell with

Blue Eyes Intelligence Engineering \& Sciences Publication 
straight and interdigitated flow fields were investigated by Um and Wang [5]. They attempted to provide an in-depth understanding of how a three-dimensional flow and transport phenomenon in the air cathode affect the electrochemical reaction in both of the considered channels.

Their results indicate that forced convection compelled by the interdigitated geometry significantly increased the mass transport of oxygen to, and water removal from, the catalyst layer. This trend caused a higher mass transport as related to the straight flow field.

The Simplified Conjugate Gradient Method (SCGM) was employed by Jang et al. [6] to determine the optimal locations of the baffles installed in the channels where the maximum average current density of the flow field occurred. The optimization algorithm shows a $14 \%$ increase of the output electric current from the fuel cell. Haraldsson and Wipke [7] presented some advantages and disadvantages of commercial models of many PEM fuel cells. They also explained the model selection criteria for an adequate fuel cell model and matched the selected model with what proposed by others.

An in-detailed study of flow field layouts was developed by Li and Sabir [8]. They found that the bipolar plate is the main part of a PEM fuel cell, which supplies fuel and oxidant to reactive sites, removes reaction products, collects the produced current, and provides mechanical support for the cells in the stack. Cheng and Lin [9] numerically investigated the influence of some geometrical parameters on the channels of a six-cell PEM fuel cell stack using a commercial software, CFD-ACE+. They conducted another study on the width to the height ratio of gas channels to recognize the uniform distribution of the reactant gases in the cells. Their results also show a $16.5 \%$ increase in the performance of the considered fuel cell.

Other studies on three-dimensional, two-phase, and non-isothermal PEMFCs, with parallel, interdigitated and serpentine flow patterns were carried out by Wang et al. [10-15]. They investigated the influence of the width to the rib ratio, channel aspect ratio, active area, the number of flow channel bend, and the channel cross-section area on the performance of the considered PEM. Some of their main findings from the study included: the cell performance increasing as the number of flow channel bends enhanced for the single serpentine flow field; the single serpentine flow field had higher electric output in comparison to the double and triple serpentine flow field; and the cell performance was gradually improved as the flow channel widened.

The principles of modeling, controlling, and assembling a PEM fuel cell battery system were presented by Zhang and Zhou [16]. The dynamic behaviors of a boost DC/DC converter, PEM fuel cell stack, and a lithium-ion battery were described by their proposed simulation model. Garus and Malecki [17] also proposed a simulation model of a PEM fuel cell under consideration to empower an autonomous underwater vehicle. In another study, Garus and Polak [18] investigated a static mathematical model of a real hydrogen-oxygen PEM fuel cell stack in which its parameters were extracted from the genetic algorithm approach using empirical data provided during the process.

A comprehensive study of models, varying from one-dimensional, single-component to fully three-dimensional, large-scale setups, was conducted by
Siegel [19]. According to the numerical investigation of the proton exchange membrane fuel cells, done by Cheng et al. [20], some geometrical parameters of a problem involving the gas channel width, height, and the thickness of the gas diffusion layer were optimized. Their optimization algorithm presents a unique set of geometric parameters regardless of the initial estimate. Siracusano et al. [21] experimentally found an admirable performance of $4 \mathrm{~A} / \mathrm{cm}^{2}$ at $1.9 \mathrm{~V}$ and $90^{\circ} \mathrm{C}$, for an Aquivion short-side chain perfluoro-sulfonic acid membrane electrolyzer installed in a PEM electrolyzer in the presence of a moderate metal-loading. They showed that Aquivion provided an enhancement in performance versus the Nafion membrane. In another attempt [22], a current density larger than $3 \mathrm{~A} / \mathrm{cm}^{2}$ was also achieved in electrolysis cells with efficiency larger than $80 \%$. They also showed a degradation rate of less than $5 \mu \mathrm{V} / \mathrm{h}$ in a 1000 h durability test at $1 \mathrm{~A} / \mathrm{cm}^{2}$.

In this research, the influence of the cross-section area of the channels (see Figure 2), inlet gas humidity, and temperature on the performance of a PEMFC are numerically simulated. Both of rectangular and triangular ducts have two flow patterns: parallel and counterflow. After a grid independence study, a comparison is carried out between the provided results and available numerical and experimental data. All geometrical parameters are selected regarding reference [23].
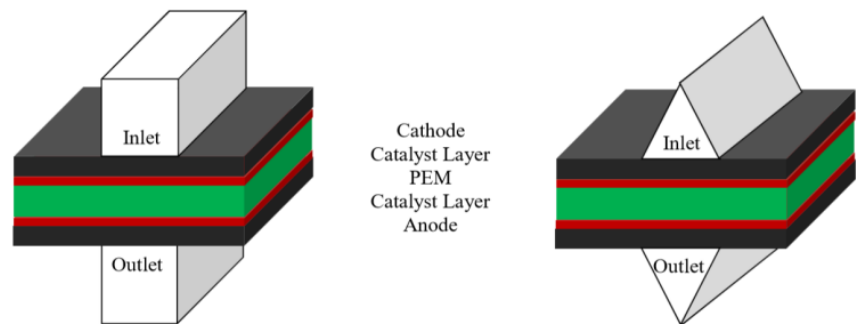

Fig. 2.Two considered channels with retangular and triaglar cross-sectional areas.

\section{INITIAL ASSUMPTIONS OF THE SIMULATION AND GOVERNING EQUATIONS}

The numerical analysis includes continuity, momentum, energy, and other related equations for the simulation of the transport phenomenon of passing gases through the channels of the considered PEM. The equations of electron and proton transports should be solved to predict the density distributions of the electric current. Some fundamental assumptions made during all simulations to modify the numerical modeling are listed as follows:

- The numerical simulation is carried out at an unsteady state.

- The fluid flows through the channels, a Gas Diffusion Layer (GDL), and membranes are assumed to be incompressible and remain in the laminar flow regime.

- The GDL and Catalyst Layer (CL) are assumed isotropic and are homogeneous porous media. Furthermore, their porosity and permeability are treated as constant values. 
- The thermophysical and electrochemical characteristics of the gases and the other components are assumed to be constant values during the simulations and throughout the ducts.

- The effects of gravity, contact resistance, and thermal resistance between layers are insignificant.

- The fuel gas and the air injected into the PEM are moisture-saturated.

- Moisturized inlet air is treated as an ideal gas.

The continuity and momentum equations for the gaseous species which are derived from [24-26] are presented below:

$\frac{\partial(\rho \varepsilon)}{\partial \mathrm{t}}+\nabla \cdot(\varepsilon \rho \overrightarrow{\mathrm{u}})=0$

(1)

$\frac{\partial(\rho \varepsilon \vec{u})}{\partial \mathrm{t}}+\nabla \cdot(\varepsilon \rho \overrightarrow{\mathrm{u}} \overrightarrow{\mathrm{u}})=-\varepsilon \nabla \mathrm{p}+\nabla \cdot(\varepsilon \mu \nabla \overrightarrow{\mathrm{u}})+\mathrm{S}_{\mathrm{u}}$

(2)

where the source term Su is defined for all layers as $-\frac{\mu}{\mathrm{k}} \varepsilon^{2} \vec{\mu}$.

The energy equation is as follows [26]:

$\frac{\partial(\rho \vec{u}(E))}{\partial \mathrm{t}}+\nabla \cdot((E) \rho \vec{u} \vec{u})=\nabla \cdot\left(\lambda_{\text {eff }} \nabla T-\sum_{k} h_{k} X_{k}+\right.$

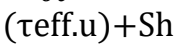

where the effective stress tensor, $\tau_{\mathrm{eff}}$, is negligible with regard to the slow velocity of the flow. Meanwhile, the effective conductivity coefficient, $\lambda_{\text {eff, }}$ is defined as $\varepsilon \lambda_{\mathrm{f}}+(1-\varepsilon) \lambda_{\mathrm{f}}$ and subscripts ' $\mathrm{f}$ ' and 's' indicate fluid and solid phases respectively. In the energy equation, the source term $S_{h}$ is defined as $\frac{\left|j_{c}\right|}{2 F} T|\Delta s|+\left|j_{c} \eta_{c}\right|$ for the cathode of GDL and $I^{2} / k$ for the membrane layer where $j_{c}$ is the transfer current, $\eta$ is the electrode over-potential, and I is the net current density presented by [27].

\section{PROBLEM DESCRIPTION, GRID INDEPENDENCY, AND NUMERICAL VALIDATION}

Based on the presented experimental and numerical results of the previous studies cited in the introduction, this research aims to provide a database of PEM efficiency and how it is affected by the main variables, including the channel cross-section areas; rectangular and triangular, and the humidity and temperature of the inlet gases. All parts of the considered PEM fuel cell is illustrated in Figure 3.

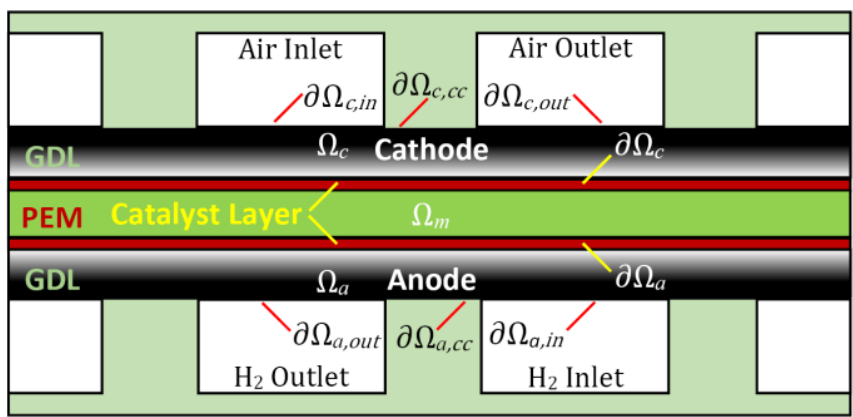

Fig. 3.The schematic of the problem under consideration and its parts.

According to Figure 3, a computational domain includes three distinct volumes: the anode $\left(\Omega_{a}\right)$, the cathode $\left(\Omega_{c}\right)$ and the membrane $\left(\Omega_{m}\right)$. There are also eight surfaces involved in
Published By:

Blue Eyes Intelligence Engineering \& Sciences Publication

(C) Convriaht: All riahts reserved.

a computational domain: input to the cathode gas diffusion layer $\left(\partial \Omega_{c, i n}\right)$, output from the cathode gas diffusion layer $\left(\partial \Omega_{c, \text { out }}\right)$, input to the anode gas diffusion layer $\left(\partial \Omega_{a, i n}\right)$, output from the anode gas diffusion layer $\left(\partial \Omega_{a, o u t}\right)$, the contact area of the cathode catalyst $\left(\partial \Omega_{c}\right)$, the contact area of the anode catalyst $\left(\partial \Omega_{a}\right)$, the contact area between the cathode and bipolar plate $\left(\partial \Omega_{c, c c}\right)$ and the contact area between the anode and bipolar plate $\left(\partial \Omega_{a, c c}\right)$. All variables and constant parameters, including geometrical and thermo-physical values used in the simulations are listed in Table I.

Table- I: The key geometrical and thermos-physical parameters used in all simulations.

\begin{tabular}{|c|c|}
\hline Description (Symbol), Dimension (if any) & $\begin{array}{l}\text { Value } \\
\text { (if any) }\end{array}$ \\
\hline Anode channel height, m & $1.0 \times 10^{-3}$ \\
\hline Anode channel length, m & $1.1 \times 10^{-3}$ \\
\hline Anode channel width, m & $1.0 \times 10^{-3}$ \\
\hline Anodic exchange current density $\left(j_{a, r e f}\right), \mathrm{A} \mathrm{m}^{-3}$ & $9.227 \times 10^{8}$ \\
\hline Anode inlet pressure (P), $\mathrm{Pa}$ & 101,325 \\
\hline Bruggemann coefficient of catalyst layer $\left(\xi_{C L}\right)$ & 1.5 \\
\hline Bruggemann coefficient of gas diffusion layer $\left(\xi_{G D L}\right)$ & 1.5 \\
\hline Cathode channel height, m & $1.0 \times 10^{-3}$ \\
\hline Cathode channel length, $\mathrm{m}$ & $1.1 \times 10^{-3}$ \\
\hline Cathode channel width, m & $1.0 \times 10^{-3}$ \\
\hline Cathode exchange current density $\left(j_{c, r e f}\right), \mathrm{A} \mathrm{m}^{-3}$ & $1.05 \times 10^{6}$ \\
\hline Cathode inlet pressure (P), $\mathrm{Pa}$ & 101325 \\
\hline Catalyst layer thickness $\left(t_{C L}\right), \mathrm{m}$ & $10 \times 10^{-6}$ \\
\hline Condensation rate constant $\left(k_{e}\right), \mathrm{s}^{-1}$ & 100 \\
\hline Density $(\rho), \mathrm{kg} \mathrm{m}^{-3}$ & $1.0 \times 10^{-3}$ \\
\hline Dynamic viscosity $(\mu), \mathrm{kg} \mathrm{m} \mathrm{s}^{-1}$ & $0.005 \times 10^{-3}$ \\
\hline Electronic conductivity of catalyst layer, $\Omega^{-1} \mathrm{~m}^{-1}$ & 53 \\
\hline Electronic conductivity of gas diffusion layer, $\Omega^{-1} \mathrm{~m}^{-1}$ & 53 \\
\hline Evaporation rate constant, atm ${ }^{-1} \mathrm{~s}^{-1}$ & 100 \\
\hline Faraday constant $(\mathrm{F}), \mathrm{C} \mathrm{mol}^{-1}$ & 96,487 \\
\hline Gas diffusion layer thickness $\left(t_{G D L}\right), \mathrm{m}$ & $0.3 \times 10^{-3}$ \\
\hline Membrane thickness $\left(t_{M}\right), \mathrm{m}$ & $50 \times 10^{-6}$ \\
\hline Permeability of the catalyst layer $\left(k_{C L}\right), \mathrm{m}^{2}$ & $1.76 \times 10^{-11}$ \\
\hline Permeability of the gas diffusion layer $\left(k_{G D L}\right), \mathrm{m}^{2}$ & $1.76 \times 10^{-11}$ \\
\hline Permeability of the membrane $\left(k_{M}\right), \mathrm{m}^{2}$ & $1.76 \times 10^{-18}$ \\
\hline Pressure (P), $\mathrm{Pa}$ & 101,325 \\
\hline Porosity of the catalyst layer $\left(\varepsilon_{C L}\right)$ & 0.4 \\
\hline Porosity of gas diffusion layer $\left(\varepsilon_{G D L}\right)$ & 0.5 \\
\hline Porosity of the membrane $\left(\varepsilon_{M}\right)$ & 0.28 \\
\hline Relative humidity of inlet stream (RH), \% & $10,50,100$ \\
\hline Time (t), s & N/A \\
\hline \multicolumn{2}{|l|}{ Volumes } \\
\hline \multicolumn{2}{|l|}{ Anode $\left(\Omega_{a}\right)$} \\
\hline \multicolumn{2}{|l|}{ Cathode $\left(\Omega_{c}\right)$} \\
\hline Membrane $\left(\Omega_{m}\right)$ & \\
\hline
\end{tabular}

Published By:
Blue Eyes Intelligence Engineering
\& Sciences Publication
Convriaht: All riahts reserved.



Cross-Section Area Channels

\begin{tabular}{|c|c|}
\hline \multicolumn{2}{|l|}{ Surfaces } \\
\hline \multicolumn{2}{|l|}{ Contact surface anode catalyst $\left(\partial \Omega_{a}\right)$} \\
\hline \multicolumn{2}{|l|}{ Contact surface between anode and bipolar $\left(\partial \Omega_{a, c c}\right)$} \\
\hline \multicolumn{2}{|l|}{ Contact surface cathode catalyst $\left(\partial \Omega_{c}\right)$} \\
\hline \multicolumn{2}{|l|}{ Contact surface between cathode and bipolar $\left(\partial \Omega_{c, c c}\right)$} \\
\hline \multicolumn{2}{|l|}{ Input to anode gas diffusion layer $\left(\partial \Omega_{a, i n}\right)$} \\
\hline \multicolumn{2}{|l|}{ Input to cathode gas diffusion layer $\left(\partial \Omega_{c, i n}\right)$} \\
\hline \multicolumn{2}{|l|}{ Output from anode gas diffusion layer $\left(\partial \Omega_{a, \text { out }}\right)$} \\
\hline \multicolumn{2}{|l|}{ Output from cathode gas diffusion layer $\left(\partial \Omega_{c, \text { out }}\right)$} \\
\hline \multicolumn{2}{|l|}{ Simulation Conditions } \\
\hline Anode inlet mass fraction ratio $\left(m_{\mathrm{H}_{2}}: m_{\mathrm{H}_{2} \mathrm{O}}\right)$ & 0.83:0.17 \\
\hline Anode inlet hydrogen velocity $\left(\mathrm{U}_{a}\right), \mathrm{m} \mathrm{s}^{-1}$ & $51 \times 10^{-6}$ \\
\hline Cathode inlet mass fraction ratio $\left(m_{\mathrm{N}_{2}}: m_{\mathrm{O}_{2}}: m_{\mathrm{H}_{2} \mathrm{O}}\right)$ & $\begin{array}{l}0.54: 0.19: 0.2 \\
7\end{array}$ \\
\hline Cathode inlet air velocity $\left(\mathrm{U}_{\mathrm{c}}\right), \mathrm{m} \mathrm{s}^{-1}$ & $1.1 \times 10^{-3}$ \\
\hline Cell temperature $\left(\mathrm{T}_{\text {cell }}\right), \mathrm{K}$ & 323 \\
\hline
\end{tabular}

The governing equations (1) to (3) must be solved to find velocity, pressure, and temperature fields. Therefore, the continuity, momentum, and energy equations are discretized numerically according to the Finite Volume Method (FVM). The SIMPLEC algorithm presented by Patankar [28] is employed for linking between velocity and pressure in the momentum equation. Third-order upwind and second-order central difference schemes are utilized to simulate the convective and source terms available in the governing equations.

Before the simulation, all suitable initial and boundary conditions and cell voltages are employed. Then, the ionic phase and electronic phase potentials are obtained, and the difference between them is referred to an electrode over-potential. Eventually, the species equation is solved to determine the distribution of each key parameter. All steps should be repeated to achieve a convergence criterion equal to $1 \times 10^{-5}$. This means that the residuals of all the variables must be less than the convergence criterion.

Grid independence is performed to realize an optimal number of the mesh and the influence of the number of cells on the output current density. Five non-uniform cases of mesh, with 580000, 715000, 925000, 1062448, and 1300000 cells are provided to recognize the independent grid number where the smallest cell size is $0.005 \mathrm{~mm}$ adjacent to the solid walls of ducts. The variation of the output current density, versus the five mentioned grid numbers, is illustrated in Figure 4 for voltages of 0.3 (left axis) and 0.75 (right axis), with a rectangular channel and a parallel flow. As seen, there is a negligible deviation between the provided results for the grid numbers 1062448 and 1300000. Therefore, the grid number of 1062448 is selected to minimize the computational time for all of the simulations.

Figure 5 shows a comparison between output the current density as the PEM efficiency versus the voltage for rectangular duct at different inlet gas conditions. As it seen, the output current density decreases when the voltage decreases too and this trend follows the other numerical and experimental results. The maximum deviation for $\mathrm{T}_{\mathrm{in}}=70^{\circ} \mathrm{C}$ and $\mathrm{RH}=100 \%$ is $10 \%$.

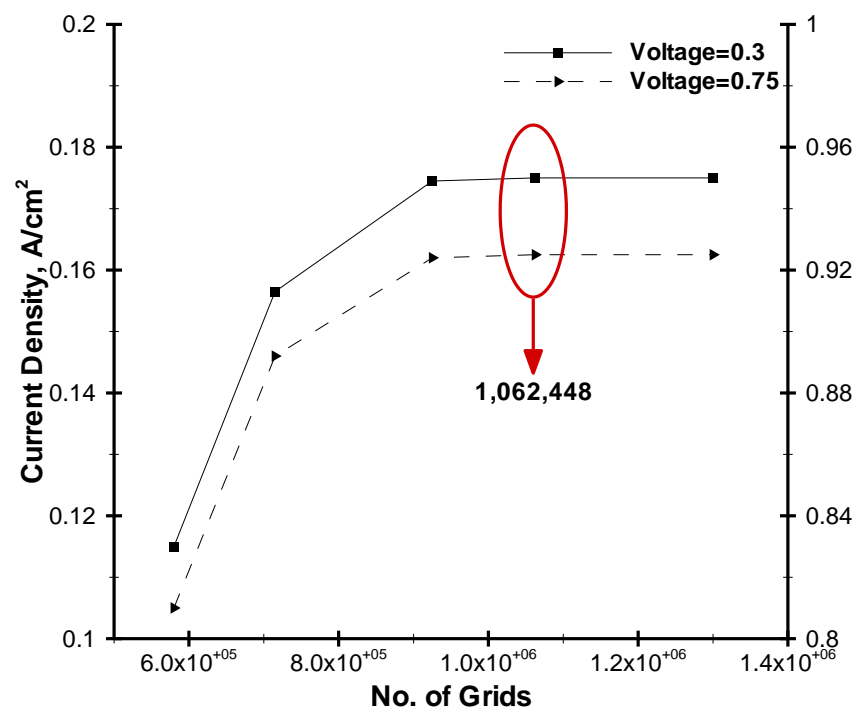

Fig. 4.Current density variation versus the number of grids for $\mathrm{V}=0.3$ (left axis) and $\mathrm{V}=0.75$ (right axis).

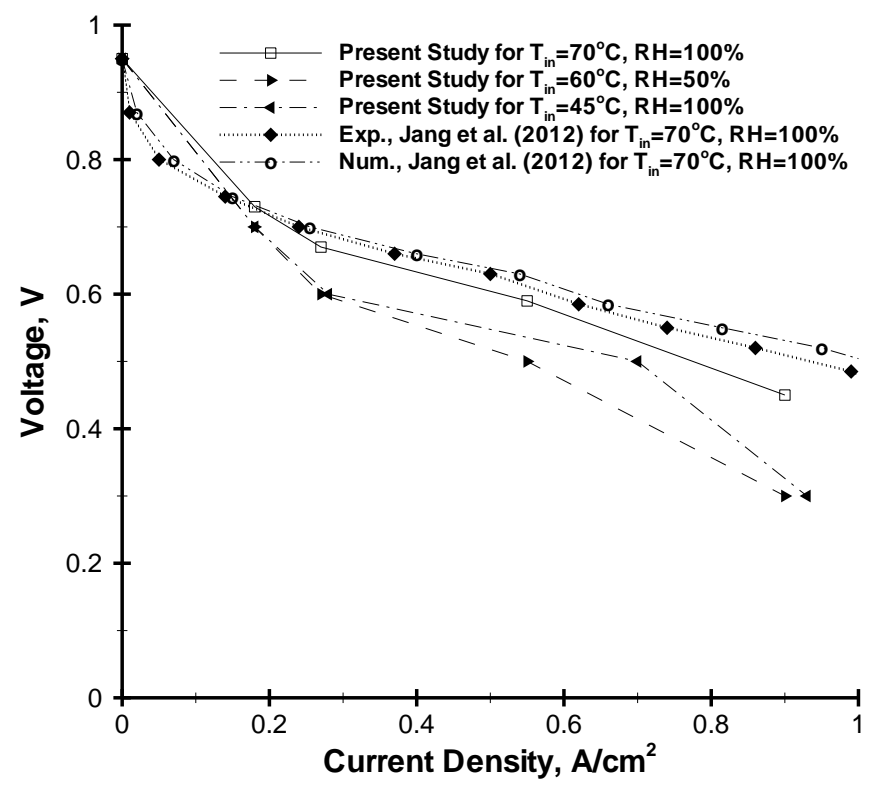

Fig. 5.The comparison of PEM efficiency between the provided results and the available numerical and experimental data for rectangular duct and parallel flow.

\section{RESULTS AND DISCUSSION}

The governing equations are solved using a numerical method and discussion regarding the numerical prediction are examined in this section. The output voltages of the simulated PEMFC with two ducts, rectangular and triangular, are predicted by Figure 6 . The results show small discrepancies between the voltage predictions in the rectangular duct in comparison with the triangular duct. This indicates a higher output voltage for specific currents in the triangular duct rather than the rectangular. This discrepancy only arises with the choice of parallel flow in the PEMFC and does not affect the output voltage in the counterflow case (see Figure 7).

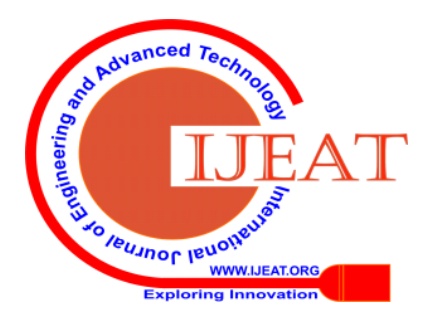




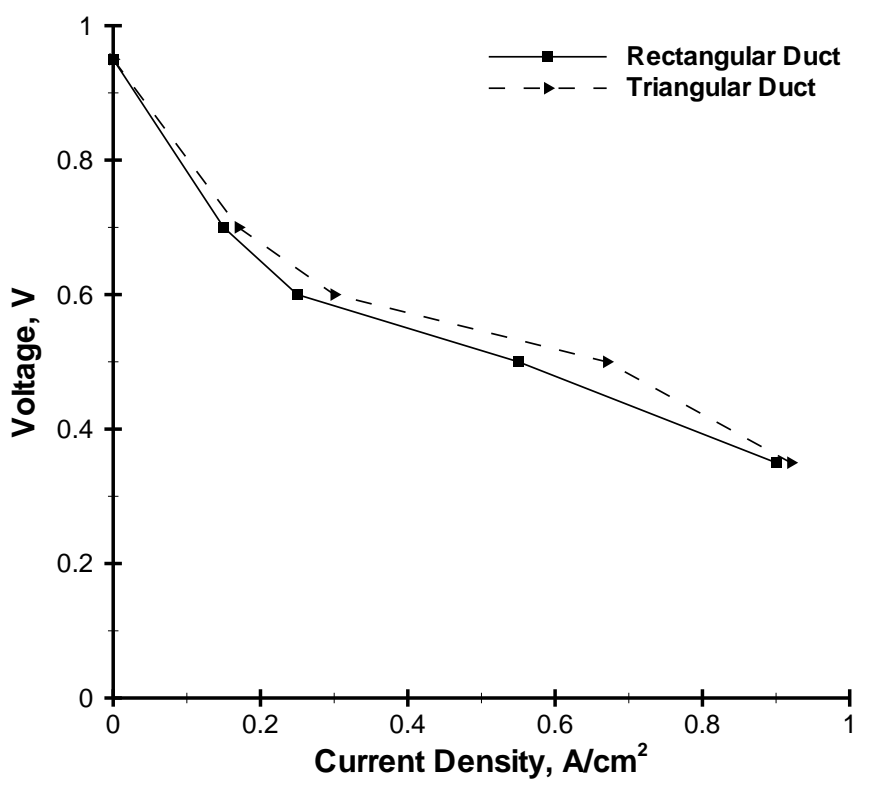

Fig. 6. The influence of duct shape on the output voltage for a relative humidity of $50 \%$ and parallel flow.

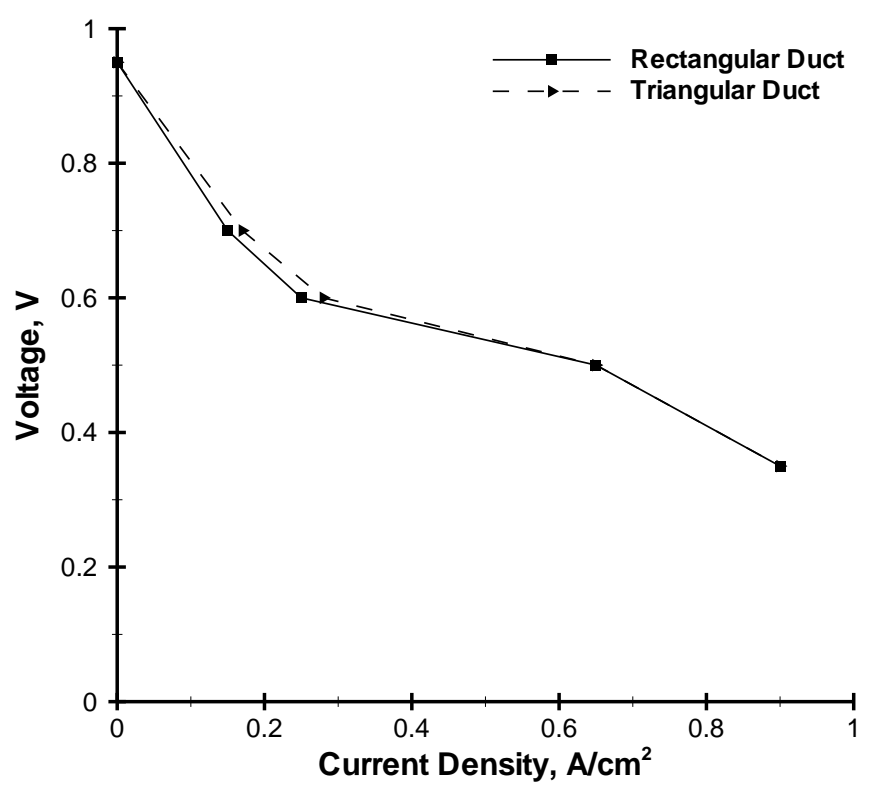

Fig. 7.The influence of duct shape on the output voltage for a relative humidity of $\mathbf{5 0 \%}$ and counterflow.

The effect of relative humidity on the output voltage of PEMFC is shown in Figures 8 and 9. As demonstrated by the prediction model, the effect of relative humidity on the output voltage leads to discrepancies of up to $40 \%$ in rectangular duct. High relative humidity causes higher output voltage in most cases. A similar trend is found for both parallel and counter flows as well as for both rectangular and triangular ducts. These differences are evaluated to be less at the low-current densities in comparison with high-current densities. In general, counter flow case with higher relative humidity leads to a higher output voltage in comparison with the parallel flow in current density (much more than 0.2 $\mathrm{A} / \mathrm{cm}^{2}$ ). In small range current densities (less than 0.2 $\mathrm{A} / \mathrm{cm}^{2}$ ), the parallel flow with the same relative humidity rate shows a higher output voltage; however, the deviation between the output voltages for both flows are low. Further, the trend of change of voltages for both type of channels is the same, but in the triangle channel the difference between

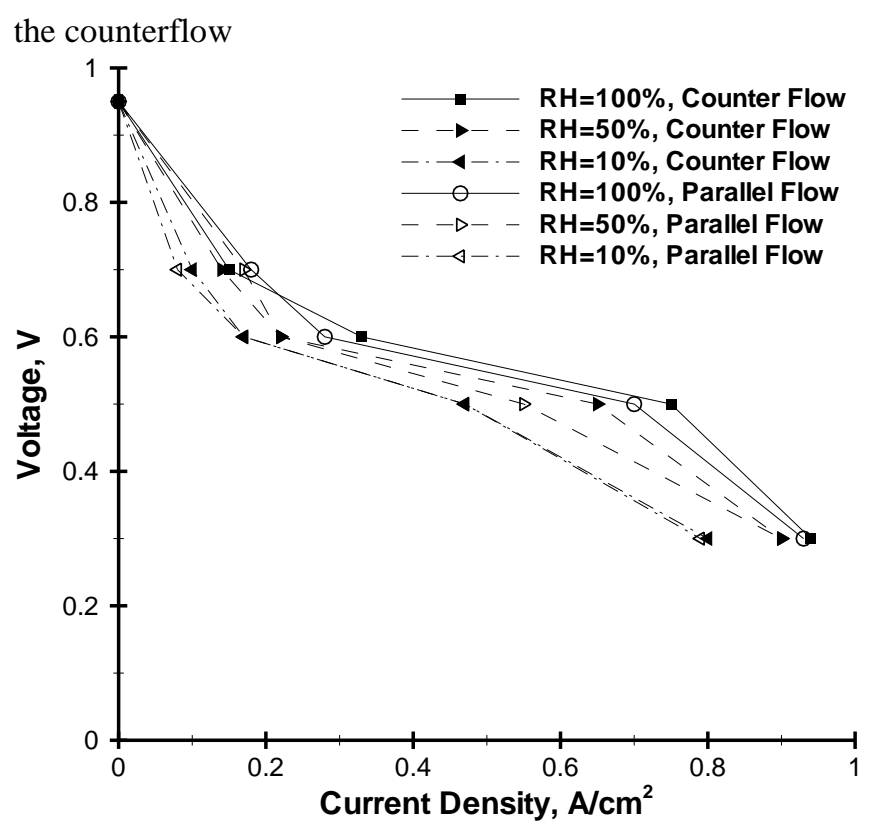

Fig. 8.The influence of relative humidity of input gas on the output voltage for rectangular duct and both flow directions.

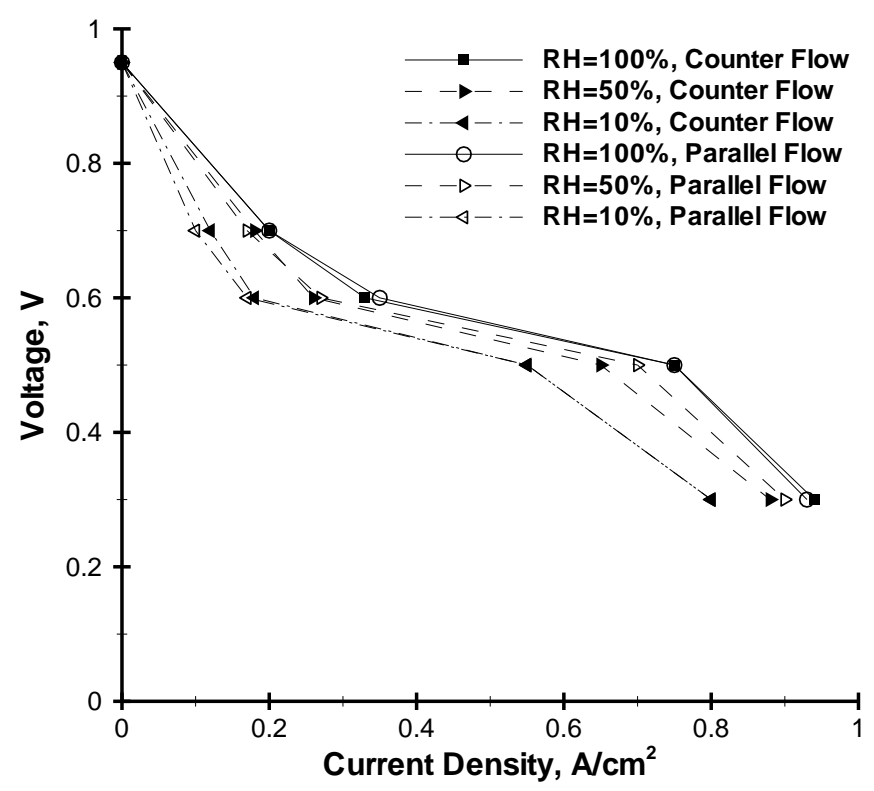

Fig. 9. The influence of relative humidity of input gas on the output voltage for triangular duct and both flow directions.

and parallel flow are negligible and both flows produce a same voltage in a same relative humidity rate.

In addition, the effects of various inlet gas temperature on the output voltage are predicted for both triangular and rectangular ducts. As shown in Figures 10 and 11 for triangular and rectangular ducts, respectively, an increase in inlet gas temperature leads to the higher output voltage. A $15^{\circ} \mathrm{C}$ difference in the inlet gas temperature makes a $10 \%$ difference in output voltage in the most cases. Comparison between the output voltage results between two rectangular and triangular ducts indicates that the rectangular duct produces less output voltage (about 20\%).

Published By:

Blue Eyes Intelligence Engineering \& Sciences Publication

(C) Convriaht: All riahts reserved. 


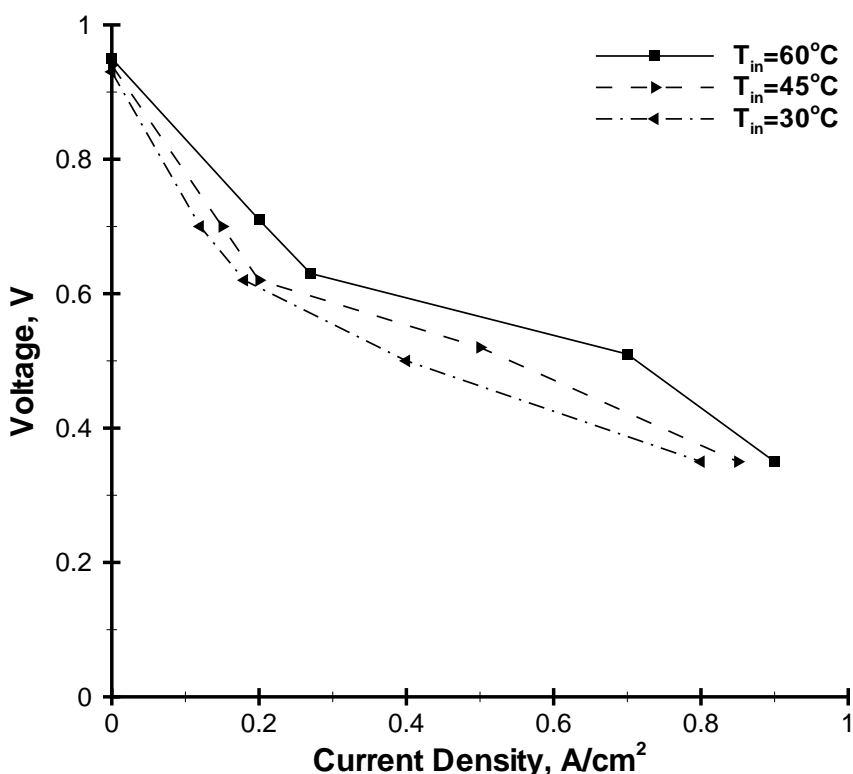

Fig. 10. The influence of inlet gas temperature on the output voltage for triangular duct and parallel flow.

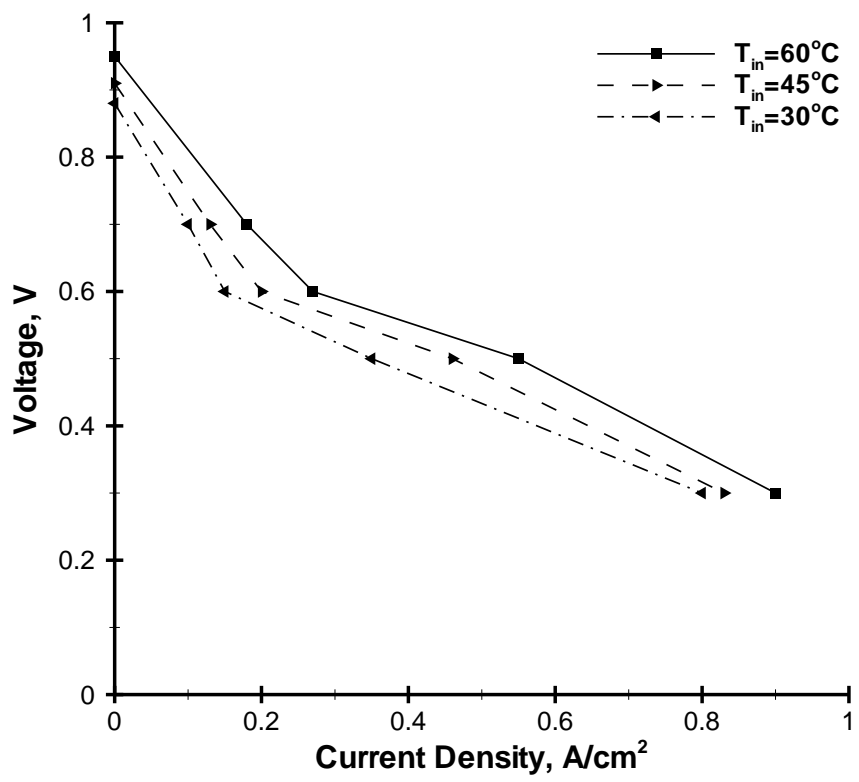

Fig. 11. The influence of inlet gas temperature on the output voltage for rectangular duct and parallel flow.

The distributions of two most important mass fractions including $\mathrm{H}_{2} \mathrm{O}$ and $\mathrm{H}_{2}$ in air inlet/outlet as well as the gas diffusion layer along the cathode/anode sides are depicted in Figure 11 for $\mathrm{V}=0.7$. According to the governing equations of a fuel cell, oxygen magnitude due to its consumption decreases and the amount of water is increased. This trend is illustrated by Figure 12 where the highest value of $\mathrm{H}_{2} \mathrm{O}$ is near the CL recording a $75 \%$ increase in comparison to the inlet. At this voltage, extra water blocks the porous layer of the gas diffusion layer and prevents the effective penetration of oxygen in the CL of the cathode side. On the anode side, $\mathrm{H}_{2}$ gas as the fuel inlet diffuses to the anode CL where it later separates into protons and electrons for producing an electric current. The maximum difference between hydrogen through travelling from the inlet to the outlet is about $30 \%$.

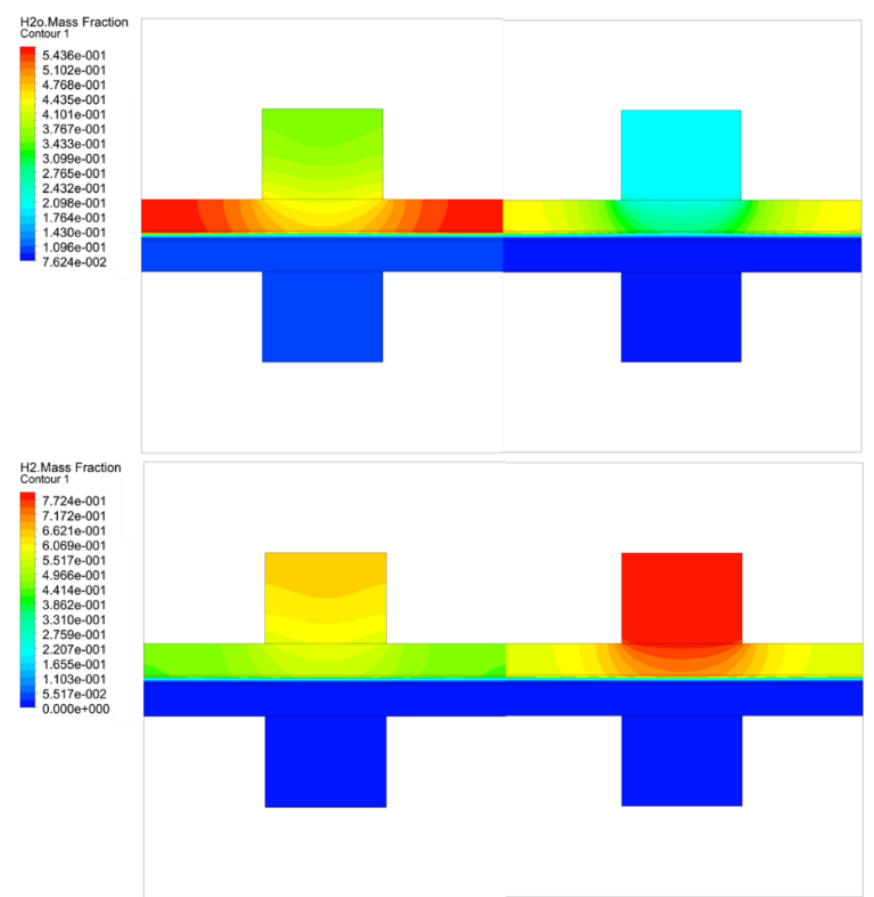

Fig. 12. The contours of $\mathrm{H}_{2} \mathrm{O}$ and $\mathrm{H}_{2}$ inlet gases through the cathode/anode.

\section{CONCLUSIONS AND FUTURE SCOPE}

The performance of PEM with two different geometries is investigated in this study. Two different geometries; rectangular and triangular ducts are applied to the PEM design to explore how these geometries affect the PEM performance. The study contains the effect of humidity and temperature of input gas as two other effective parameters on the PEM operation. Furthermore, two different types of flow direction; parallel and counterflows are considered in this study. As the results indicate, the high temperature and humidity of the inlet gas produce much higher output voltage with different current densities in all simulations. Further, both cross-section areas outline almost the same output voltage under the same conditions with the difference of less than 2\%, which indicates the difference between cross-section areas (triangular and rectangular) does not significantly affect the performance of the PEM. It should be noted that when the temperature and the humidity of the inlet gas are increased, the difference between two channels becomes higher. As under these circumstances, triangular cross-section channel produces higher performance in comparison to the rectangular.

In addition, the difference between the types of flows (counter and parallel) leads to deviation on the output voltage for the same conditions. Generally, the counter type of flow produces a higher output voltage in comparison with the parallel flows, which in triangular cross-section type of area this becomes more apparent rather than the rectangular.

\section{ACKNOWLEDGMENT}

We are very grateful to FRGS/1/2016/TK03/UKM/03/1 grant by the Ministry of Education, Malaysia (MoE).

Published By:

Blue Eyes Intelligence Engineering \& Sciences Publication

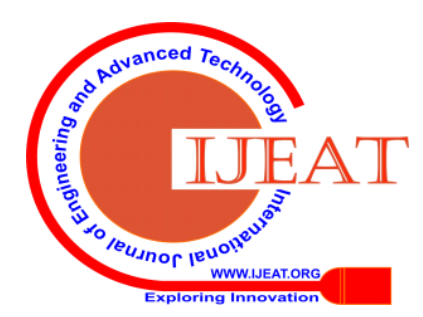




\section{REFERENCES}

1. J. Larminie, and A. Dicks, Fuel Cell Systems Explained. 2nd ed., John Willey \& Sons Ltd., Chichester, 2003.

2. J.T. Pukrushpan, A.G. Stefanopoulou, and H. Peng, Control of Fuel Cell Power Systems, Advances in Industrial Control. Springer, 2004.

3. F. Barbir, PEM Fuel Cells: Theory and Practice. Elsevier, California, 2005.

4. S.W. Cha, R.O. Hayre, Y. Saito, and F.B. Prinz, "The scaling behavior of flow patterns: a model investigation," Journal of Power Sources, vol. 134(1), 2004, pp. 57-71.

5. S. Um, and C.Y. Wang, "Three-dimensional analysis of transport and electrochemical reactions in polymer electrolyte fuel cells," Journal of Power Sources, vol. 125(1), 2004, pp. 40-51.

6. J.Y. Jang, C.H. Cheng, and Y.X. Huang, "Optimal design of baffles locations with interdigitated flow channels of a centimeter-scale proton exchange membrane fuel cell," International Journal of Heat and Mass Transfer, vol. 53(4), 2010, pp. 732-743.

7. K. Haraldsson, and K. Wipke, "Evaluating PEM fuel cell system models," Journal of Power Sources, vol. 126(1-2), 2004, pp. 88-97.

8. X. $\mathrm{Li}$, and I. Sabir, "Review of bipolar plates in PEM fuel cells: Flow-field designs, International Journal of Hydrogen Energy," vol. 30(4), 2005, pp. 359-371.

9. C.H. Cheng, and H.H. Lin, "Numerical analysis of effects of flow channel size on reactant transport in a proton exchange membrane fuel cell stack, Journal of Power Sources," vol. 194(1), 2009, pp. 349-359.

10. X.D. Wang, Y.Y. Duan, W.M. Yan, and X.F. Peng, "Effects of flow channel geometry on cell performance for PEM fuel cells with parallel and interdigitated flow fields," Electrochimica Acta, vol. 53(16), 2008, pp. 5334-5343.

11. X.D. Wang, Y.Y. Duan, W.M. Yan, and X.F. Peng, "Local transport phenomena and cell performance of PEM fuel cells with various serpentine flow field designs," Journal of Power Sources, vol. 175(1), 2008, pp. 397-407.

12. X.D. Wang, Y.X. Huang, C.H. Cheng, J.Y. Jang, D.J. Lee, W.M. Yan, and A. Su, "Flow field optimization for proton exchange membrane fuel cells with varying channel heights and widths," Electrochimica Acta, vol. 54(23), 2009, pp. 5522-5530.

13. X.D. Wang, Y.Y. Duan, W.M. Yan, D.J. Lee, A. Su, and P.H. Chi, "Channel aspect ratio effect for serpentine proton exchange membrane fuel cell: Role of sub-rib convection," Journal of Power Sources, vol. 193(2), 2009, pp. 684-690.

14. X.D. Wang, X.X. Zhang, W.M. Yan, D.J. Lee, and A. Su, "Non-isothermal effects of single or double serpentine proton exchange membrane fuel cells," Electrochimica Acta, vol. 55(17), 2010, pp. 4926-4934.

15. X.D. Wang, W.M. Yan, Y.Y. Duan, F.B. Weng, G.B. Jung, and C.Y. Lee, "Numerical study on channel size effect for proton exchange membrane fuel cell with serpentine flow field," Energy Conversion, and Management, vol. 51(5), 2010, pp. 959-968.

16. Y. Zhang, and B. Zhou, "Modeling and control of a portable proton exchange membrane fuel cell-battery power system," Journal of Power Sources, vol. 196(20), 2011, pp. 8413-8423.

17. J. Garus, and J. Malecki, "Modeling of Fuel Cell Energy System for Use in AUV," International Journal of Arts \& Sciences, vol. 6(3), 2013, pp. $15-22$.

18. J. Garus, and A. Polak, "Simulation Model of PEM Fuel Cell Operating at Hydrogen and Oxygen," Advances in Intelligent Systems and Computing, vol. 317, 2015, pp. 31-39.

19. C. Siegel, "Review of computational heat and mass transfer modeling in polymer-electrolyte-membrane (PEM) fuel cells," Energy, vol. 33(9), 2008, pp. 1331-1352.

20. C.H. Cheng, H.H. Lin, and G.J. Lai, "Design for geometric parameters of PEM fuel cell by integrating computational fluid dynamics code with optimization method," Journal of Power Sources, vol. 165(2), 2007, pp. 803-813.

21. S. Siracusano, V. Baglio, E. Moukheiber, L. Merlo, and A.S. Aricò, "Performance of a PEM water electrolyzer combining an IrRu-oxide anode electrocatalyst and a short-side chain Aquivion membrane," International Journal of Hydrogen Energy, vol. 40(20), 2015, pp 14430-14435.

22. S. Siracusano, V. Baglio, N. Van Dijk, L. Merlo, and A.S. Aricò, "Enhanced performance and durability of low catalyst loading PEM water electrolyzer based on a short-side chain perfluorosulfonic ionomer," Applied Energy, vol. 192(15), 2017, pp. 477-489.

23. J.Y. Jang, C.H. Cheng, W.T. Liao, Y.X. Huang, and Y.C. Tsai, "Experimental and numerical study of proton exchange membrane fuel cell with spiral flow channels," Applied Energy, vol. 99, 2012, pp. 67-79. fuel cells with parallel, Interdigitated or serpentine designs," entronal of Hydrogen Energy, 34, 2009, pp.

X.D. Wang, Y.X. Huang, C.H. Cheng, J.Y. Jang, D.J. Lee, W.M. Yan, Hydrogen Energy, vol. 35(9), 2010, pp. 4247-4257.

26. P.K. Jithesh, A.S. Bansode, T. Sundararajan, and S.K. Das, "The effect of flow distributors on the liquid water distribution and performance of a PEM fuel cell," International Journal of Hydrogen Energy, vol. 37,

R.B. Bird, W. Stewart, and E.N. Lightfoot, Transport Phenomena. New

S.V. Patankar, "A calculation procedure for two-dimensional elliptic

\section{AUTHORS PROFILE}

Amin Etminan, is currently completing Ph.D. in Mechanical Engineering in Memorial University of Newfoundland (MUN), Canada. He graduated with BSc and MSc from Persian Gulf University in 2004 and Yazd University in 2007 respectively. Prior to pursuing his study in MUN, he has worked as a faculty member and the head of mechanical engineering department in Azad University for 11 years. He has been working as a P.Eng. for the inspection, design and the installment of HVAC equipment in residential buildings as well. He has published over 50 articles in peer-reviewed conference proceedings and was awarded Top Research Award in Azad University in 2011, 2012 and 2013. He also won the Nice Presentation Award in Internationa Conference on Application of Fluid Engineer, India in 2012. He is a member of Canadian Society for Mechanical Engineering (CSME), Asia-Pacific Institute of Science and Engineering (APISE), World Society of Sustainable Environmental Engineering Society (APCBEES), Science and Engineering Institute (SCIEI), and International Association of Computer Science and Information Technology (IACSIT).

Ir. Dr. Zambri Harun, is the Head of Mechanical Engineering Programme at the Faculty of Engineering and (UKM). He graduated with BSc and MEng both from Rensselaer Polytechnic Institute, New York, the United States in 1997 and 1998 respectively. He received $\mathrm{PhD}$ in turbulence from the university of Melbourne, Australia in 2012. Prior to working at UKM, he has worked as a process engineer at Motorola (M) Sdn Bhd and as a mechanical and electrical design manager for the Design and construction of engineering consultancy services company in mechancial and electrica building works. He actively researches in turbulence, fluid mechanics conference proceedings, journals as well as chapters in books both in the and construct a wind tunnel complete with automatic control along with delicate turbulence measuring equipments such as particle image velocimetry (PIV) and hotwire anemometry. He is a professional enginee registered with the Board of Engineers and a member of the Institution of Engineers, Malaysia. 